economy in the consumption of fuel by superheating the steam from the boiler in its passage through a spiral coll of tubes located in the chimney and smoke-pipe. (See Artizan for March, giving a drawing of the arrangement adopted in the Valparaiso.) Also, by using two steam cylinders of different capacities in lieu of one, into the smaller of which the steam is first admitted, expanded three times its volume, then admitted into the larger cylinder having a capacity of three times the other, when it is again expanded three times its volume, making the whole expansion nine times its original volume.

By this machine, the designers have clearly demonstrated that a veryessential saving of fuel may be attained in the case of the vessel whose dimensions and details are here given. Her consumption of fuel upon her trial, was shown to be but 2.1 tbs. per horse power per hour.

So soon as I obtain further particulars of the vessels now building by this firm, I propose to again refer to this arrangement.
Date of trial-February, 1860.
C. H.H.

\title{
CORRECTION.
}

Steamer Great Eastern.-In the details of this steamer published in the December number of the Joumal, there were the following errors and omissions, which I beg leave to correct and add.

Water wheel engines; area of grate surface, 816 square feet instead of 370 .

Propeller engines; area of grate surface, 1305 square feet instead of 406.

Additional details; decks, six forwards, five aft, and four amidships. Weight of water wheel engines and boilers, 1250 tons. Capacity for cargo, 6000 tons. Iron in hull, 10,000 tons. Plates, 30,000 in number. Rirets, $3,000,000$.

Stemer Adriatic.-In the details of this steamer published also in the December number, there was an error in the length of the boifer tubes. The correct length is 5 feet.

Additional detals; area of grate surface, 1056 feet, and the number of engines, two. C. H. H.

On the Employment of Carbon as a means of Permanent Record.* By Joun SPuiter, W. C.S., of the War Department.

The undoubted superiority, in respect to the quality of permanence, of ordinary printed characters in comparison with the several kinds of manuscript, renders it desirable that efforts should be directed to the possibility of availing ourselves of the unalterable nature of carbon, the prineipal ingredient in printer's ink, with a view to the employment of the same as a substitute for the tannate of iron in the ordinary black writing fluids. The want of permanence constantly attributed to the latter, and borne out by the inspection of manuscript deeds of comparatively recent date, seems inherent to an ink which depends solely for its permanence on a weak chemical affinity exerted between the oxides of iron and the product of a vegetable infusion, which, left to itself, is constantly undergoing change. Hence the application of dilute acids, both mineral and organic, is sufficient either to obliterate 
or render illegible the characters written with such ink; whilst its composition makes it liable to fade under circumstances no more unfavorable than that of exposure to a damp or impure atmosphere.

On the other hand, the imperishable nature of carbon, in its various forms of lamp-black, ivory black, wood charcoal, and graphite or black lead, holds out much greater promise of being usefully employed in the manufacture of a permanent writing material; since, for this substance, in its elcmentary condition, and at ordinary temperatures, there exists no solvent nor chemical reagent capable of effecting its alteration. Carbon is destroyed, or rather oxidized, only by fire, and by the long continued action of the strongest acids; only under such circumstances, therefore, as the tablet of prepared vegetable or animal substance is itself unable to withstand. Provided, then, that efficient means can be adopted for securing its perfect adhesion to the surface, or passage even in to the pores, of the paper (a point not sufficiently considered, perhaps, in the production of the so-called permanent carbon photographs), there seems evcry probability of a carbon pigment resisting the cffects of time and other corrosive influences better perhaps than any other substance, elementary or compound, which is likely to be brought into comparison with it. The perfect state of preservation of the early engravings and pages of printed type corroborates this view; they exhibit in some instances evidence of destruction by decay of the paper itself, rather than that of the carbonaceous material forming the subject of the picture.

The suggestion relative to the mode of applying carbon to these purposes, which it is intended more particularly now to enunciate, depends on the fact of the separation of carbon from organic compounds, rich in that element, sugar, gum, \&c., by the combined operation of heat and of chemical reagents, such as sulphuric and phosphoric acids, which exert a decomposing action in the same direction; and by such means to effect the deposition of the carbon within the pores of the paper by a process of development to be performed after the fluid writing ink has been to a certain extent absorbed into its substance. A system of formation by which a considerable amount of resistance, both to chemical and external influences, appears to be secured. An ink of the following composition has been made the subject of experiment:-

Concentrated sulphuric acid, deeply colored

Water, . with indigo,

Loaf sugar,

Strong mucilage of gum arabic,
1 fluid ounce.

6 " "

1 ounce troy.

2 to 3 fluid ounce.

Writing traced with a quill or gold pen dipped in this ink dries to a pale blue color, but if now a heated iron be passed over its surface, or the manuscript held near a fire, the writing will quickly assume a jet black appearance, resulting from the carbonization of the sugar by the warm acid, and will have become so firmly engrafted into the substance of the paper as to oppose considerable difficulty to its removal or erasure by the knife. On account of the depth to which the written characters usually penetrate, the sheets of paper selected for use should be of the thickest make, and good white cartridge paper, or that known 
as "crcam laid," preferred to such as are colored blue with ultra-marine, for in the latter case a bleached halo is frequently pereeptible around the outline of the letters, indicating the partial destruetion of the coloring matter by the lateral action of the acil.

The writing produced in this manner seems indelible; it resists the action of "salts of lcmon," and of oxalic, tartaric, and diluted hydrochloric acids-agents which render nearly illegible the traces of ordinary black writing ink; ncithex do alkaline solutions exert any appreciable action on the carbon ink. This material possesses, therefore, many advantageous qualities which would recommend its adoption in cases where the question of permanence is of paramount importance; but it must, on the other hand, be allowed that such an ink, in its present form would but ineficiently fulfil many of the requirements necessary to bring it into common use. The peculiar method of development rendering the application of heat imperative, and that of a temperature somewhat above the boiling point of water, together with the circumstance that it will be found impossible with a thin sheet of paper to write on both sides, must certainly be counted among its more prominent disadvantages.

Though not perhaps capable of employment on the animal tissues, vellum and parchment, there is every probability of its successful application in connexion with the new material produced by the action of strong acids on paper, and known under the name of vegetable parchment.

Royal Arsenal, Woolwich, Dec. 5th, 1859.

\section{Extract of Hops. Houblonine.}

M. Ramont asserts that he has obtained by treating hops by boiling water in a close vessel, an extract which he calls houblonine, which contains all the active, aromatic, bitter, and astringent principles of the hops; and that by means of this extract, the manufacture of ale may be greatly ameliorated.-Cosmos, March, 1860.

\section{Deseription of Brown \& Sharpe's American Standard Wire Gauge.}

To the Editor of the Journal of the Franklin Institute.

SIr :-Lately, upon examining some boilers that had been ordered to be made from iron of No. 4 gauge, or about $\frac{1}{4}$-inch thickness, the plates were found to be only No. 6 , or two numbers less than they were expected to be; objection being urged, the constructor produced the gauge for his justification, but instead of its being the time-honored Birmingham standard gauge, it proved to be one styled "American stmdard wire gauge," made by Brown \& Sharpe, of Providence, R. I., and which, it was said, had becn adopted by many of the plate manufacturers of the United States. Now, the gauge as a measurer of boiler plate is new to the writer who has frequently under his notice the thickness of such plates, and it is desired to obtain, through the medium of 